Al-Huquq: Journal of Indonesian Islamic Economic Law, 3 (1), 2021: 1-13

ISSN: 2715-0003; E-ISSN 2714-5514

DOI: http://doi.org/10.19105/alhuquq.v3i1.4315

\title{
Kedudukan Mitra Pengemudi Ojek Online dalam Perjanjian Kemitraan (Studi Kasus Akuisisi Uber oleh Grab)
}

\author{
Muhammad Amin, Bhismoadi Tri Wahyu Faizal \\ (Fakultas Syariah, IAIN Palangkaraya, Jalan George Obos Komplek Islamic Centre, \\ Palangkaraya, Kalimantan Tengah, 73112)
}

\begin{abstract}
Abstrak:
Mitra kerja sangat penting untuk pengembangan penyedia layanan ojek online, yang selanjutnya mengarah pada kesepakatan kemitraan antara pengemudi ojek online dan penyedia layanan ojek online. Namun ketatnya persaingan bisnis ojek online di Indonesia menyebabkan kegiatan ini berjalan dinamis. Akuisisi terhadap uber yang dilakukan oleh grab merupakan bukti persaingan sengit dalam bisnis ini. Banyaknya kesalahpahaman antara pengemudi ojek online dan penyedia layanan ojek online menjadi fokus penelitian ini. Selanjutnya, penelitian ini menggunakan jenis penelitian hukum normatif dengan menggunakan pendekatan perundang-undangan dengan menjadikan perjanjian kemitraan ojek online sebagai bahan hukum primernya. Perjanjian kemitraan ini berbeda dengan perjanjian kerja pada umumnya. Sistem upah, pesanan dan pekerjaan tidak nampak jelas dalam perjanjian kemitraan ini. Selanjutnya, jika kemitraan berakhir, maka tidak akan ada pesangon dan jaminan lainnya. Sebagai kesimpulan, perjanjian kemitraan hanyalah mutualisme belaka, pengakuisisian uber menjadi penjelasan tentang posisi para pihak dalam kegiatan perjanjian kemitraan, khususnya ojek online. (Partners are essential to the development of online driver service providers, which further lead to partnership agreement estabilished between online drivers and the online driver service providers. However, businees competion in Indonesia has caused this activity to go on a dynamic direction. The acquistion of uber done by grab is a prove of this business competionn. A lot of misunderstandings between online drivers and the service providers are the focus of the study. Furthermore, this research uses a normative legal research with a stautory approach and uses legal online driver agreement material. This partnership
\end{abstract}

email koresproden: muhammad.amin@iain-palangkaraya.ac.id

https://creativecommons.org/licenses/by-nc/4.0/

Copyright (c) 2019 by al-huquq. All Right Reserved 
agreement is different than the general employment. Wages, orders and jobs are not apparent in this partnership agreement. Furthermore, if the partnership ended, there will be no severance pay either. As a conclusion, the partnership agreement is a merely mutualism, grab's acquistion of uber makes an explanation of the position of the parties in the partnership agreement)

Kata Kunci:

Kemitraan, Perjanjian Kemitraan, Ojek Online, Akuisisi Uber

\section{Pendahuluan}

Fenomena penyedia jasa kebutuhan berbasis online telah begitu menjamur di kalangan masyarakat Indonesia. Berbagai kebutuhan yang kita perlukan dapat dengan mudah kita wujudkan. Bahkan hanya dengan duduk manis di rumah lalu pesan melalui online. Kegiatan ini bermula pada jenis usaha kuliner, dimana pihak warung makan memberikan kemudahan kepada pelanggannya dengan menyediakan jasa delivery order. Terbukti, hal ini dapat meningkatkan omzet dari para pengusaha warung makan ${ }^{1}$.

Perkembangan pelayanan merupakan sebuah peluang usaha yang tidak disia-siakan oleh para penyedia jasa lainnya. Terlihat pada masa sekarang, begitu berlomba-lombanya pengusaha untuk memberikan pelayanan jasa kepada masyarakat Indonesia, mulai dari jasa loundry, bimbingan belajar, kurir, ekspedisi dan lain sebagainya. Inovasi baru, dalam bidang transportasi darat di Indonesia dengan cara online 2 . Salah satu perkembangan yang begitu masif dalam memberikan pelayanan jasa dengan cara online, ialah pada ranah ojek online. Mulai dari usaha anak bangsa dengan cakupan seluruh

1 Tita Yulia Iriani, “Analisis Dampak Layanan Go-Food Terhadap Omzet Penjualan Rumah Makan Di Kota Bandung" (Skripsi, Bandung, Pasundan, 2018).

2 Geistiar Yoga Pratama, "Perlindungan Hukum Terhadap Data Pribadi Pengguna Jasa Transportasi Online dari Tindakan Penyalahgunaan Pihak Penyedia Jasa Berdasarkan UU No 8 Tahun 1999 tentang Perlindungan Konsumen," Jurnal Masalah Hukum 5 (2016): 28. 
Indonesia yaitu Gojek, adapula Grab yang sudah mencakup sampai Asia Tenggara, dan Uber yang mencakup dunia Internasional ${ }^{3}$.

Kompetisi yang sengit diantara penyedia jasa ojek online untuk dapat menarik hati masyarakat Indonesia agar menggunakan jasa yang telah disediakannya, menyebabkan terjadinya kegiatan pengakuisisian yang dilakukan Grab pada Uber di wilayah Indonesia. Problematika yang terjadi bukanlah pada proses pengakuisisian yang dilakukan Grab, melainkan bagaimana kelanjutan status mitra pengemudi Uber pasca pengakuisisian ini, khususnya mitra pengemudi ojek online Uber.

Penyedia jasa ojek online memberikan kesempatan kepada masyarakat Indonesia untuk bergabung menjadi mitra pengemudi ojek online dengan perjanjian kemitraan. Tentu saja hal ini bertujuan untuk meningkatkan efektivitas dan efisiensi para penggunanya. Perjanjian kemitraan merupakan perjanjian yang menimbulkan simbiosis mutualisme, yaitu saling menguntungkannya masing-masing pihak ${ }^{4}$. Pihak penyedia jasa ojek online memberikan alternatif pekerjaan yang dapat dilakukan oleh mitra pengemudi ojek online, kemudian mitra pengemudi ojek online memenuhi pekerjaan yang diinginkan pengguna jasa ojek online, kemudian mitra pengemudi ojek online akan mendapatkan biaya jasa dari pengguna jasa tersebut, selanjutnya pihak penyedia jasa ojek online meminta prosentase atas pekerjaan tersebut. Bahkan sesekali, pihak penyedia jasa ojek online memberikan bonus insentif kepada mitra pengemudi ojek online yang mampu memenuhi target yang telah ditetapkan.

Vivian Lora menyimpulkan bahwasanya perjanjian kemitraan juga dapat berakhir sebelum pada tempo yang diperjanjikan. Pengakhiran perjanjian kemitraan yang terjadi dapat disebabkan oleh mitra pengemudi ojek online sendiri atau pihak penyedia jasa ojek online yang melakukan pemutusan kemitraan, dikarenakan mitra

${ }^{3}$ Ronna Nirmala, "Grab Ambil Alih Bisnis dan Aset Uber di Asia tenggara," Beritagar.id (blog), 2018, https:// beritagar.id/artikelamp/berita, .

4 Yochi Ayunita. Annalisa Yahanan dan Muhammad Syaifuddin, "Perlindungan Hukum Terhadap Pengemudi Taksi (mitra) Berbasis Online pada PT.Grab Indonesia," Fakultas Hukum Unsri Palembang, 2019, 54. 
pengemudi ojek online melakukan kecurangan seperti order fiktif dan lain sebagainya ${ }^{5}$.

Perjanjian kemitraan yang diterapkan penyedia jasa ojek online tentu saja berbeda dengan perjanjian kerja yang telah diatur dalam Undang-Undang Nomor 13 Tahun 2003 tentang Ketenagakerjaan. Seperti paparan penelitian Sonhaji yang menarik kesimpulan, perjanjian kemitraan gojek tidak dapat dinaungi oleh UndangUndang Ketenagakerjaan, karena tidak adanya unsur upah perintah dan pekerjaan. Sehingga payung hukum dari perjanjian kemitraan ini dikembalikan pada ranah perdata yaitu terkait syarat sah perjanjian dan asas-asas perjanjian ${ }^{6}$. Maka dari itu perlu adanya elaborasi terkait kedudukan mitra pengemudi ojek online dalam perjanjian kemitraan (studi kasus akuisisi Uber oleh Grab).

Terkait tujuan penelitian, ialah untuk mengetahui kedudukan mitra pengemudi ojek online dalam perjanjian kemitraan dengan penyedia jasa ojek online. Serta bagaimana kedudukan dan perlindungan hukum terhadap mitra pengemudi ojek online atas kepailitan Uber di Indonesia.

\section{Metode Penelitian}

Penelitian ini menggunakan jenis penelitian hukum normatif yang menempatkan sistem norma sebagai objek kajiannya. Dalam penelitian ini penulis menjadikan perjanjian kemitraan ojek online sebagai objek kajian.

Pendekatan penelitian yang digunakan ialah pendekatan perundang-undangan (statute approach) yang merupakan pendekatan terhadap berbagai aturan hukum yang berkaitan dengan perjanjian kemitraan ojek online, seperti KUHPerdata, Undang-Undang, KHES dan lain-lain. Adapun sifat penelitian adalah deskriptif analitik yaitu menggambarkan dengan jelas terkait kedudukan mitra pengemudi ojek online dalam perjanjian kemitraan serta bagaimana dampaknya ketika kemitraan berakhir.

5 Vivian Lora, “Tinjauan Hukum Terhadap Perjanjian Kemitraan Antara PT.Gojek Indonesia Cabang Medan Dengan Driver Gojek" (Skripsi, Sumatera Utara, Universitas Sumatera Utara, 2018).

${ }^{6}$ Sonhaji, “Aspek Hukum Layanan Ojek Online Perspektif UndangUndang Nomor 13 Tahun 2003 Tentang Ketenagakerjaan," Adminitrative law E Governance Journal 1 (4 November 2018): 371-85. 
Adapun bahan hukum yang dipergunakan dalam penelitian ini adalah bahan hukum primer, sekunder dan bahan non hukum. Dalam penelitian ini perjanjian kemitraan ojek online digunakan sebagai bahan hukum primernya. Sedangkan bahan hukum sekunder berupa semua publikasi tentang hukum terkait kemitraan ojek online yang bukan merupakan dokumen-dokumen resmi. Dan bahan non hukum adalah sumber non hukum yang membantu dalam menganalisa objek yang diteliti 7.

Dalam tahapan analisis data, penulis mengolah data yang diperoleh baik dari perjanjian kemitraan ojek online sebagai bahan hukum primer, publikasi hukum terkait kemitraan sebagai bahan sekunder dan informasi lainnya dengan menggunakan metode berpikir deduktif ${ }^{8}$. Tahap akhir dari analisis data ini adalah mengadakan pemeriksaan keabsahan data. Setelah tahap ini, penyusun melakukan tahap penafsiran data dari hasil sementara, berdasarkan kerangka teori yang telah dibangun sebelumnya sekaligus menarik kesimpulan dari hasil penelitian ${ }^{9}$.

\section{Perjanjian Kemitraan Beserta Kedudukannya.}

Eksistensi penyedia jasa ojek berbasis online menimbulkan persaingan yang kompetitif. Dikarenakan keberadaannya mampu memudahkan pengguna jasa dalam segala aktivitasnya. Pasalnya dengan layanan penyedia jasa ojek online, pengguna jasa tidak perlu lagi datang ke pangkalan ojek, namun akan langsung dijemput pada titik yang ditentukan pada aplikasi yang mereka sediakan. Hal ini merupakan salah satu layanan kemudahan dan keunggulan yang diusungnya.

Selain itu, citra negatif ojek pangkalan lambat laun mulai terdegradasi. Keramahan pengemudi ojek online secara otomatis dapat ditentukan masing-masing individu penggunanya. Sehingga

${ }^{7}$ Peter Mahmud Marzuki, Penelitian Hukum (Jakarta: Prenada Media Group, 2010).

${ }^{8}$ Imron Mustofa, “Jendela Logika dalam Berfikir: Deduksi dan Induksi sebagai Dasar Penalaran Ilmiah," EL-BANAT: Jurnal Pemikiran dan Pendidikan Islam Volume 6, Nomor 2 (Desember 2016): 122-42.

${ }^{9}$ Muhammad Amin, “Implementasi Undang-Undang Nomor 1 Tahun 2013 Terhadap Lembaga Keuangan Mikro Syariah yang Berbadan Hukum Koperasi," Jurisdictie: Jurnal Hukum dan Syariah 10 (2019): 82. 
mengandung konsekuensi mitra pengemudi ojek online untuk mengoptimalkan pelayanan kepada penggunanya, agar tidak menurunkan tingkat kepuasan pengguna. Hal ini menjadi indikator bagi penyedia jasa ojek online dalam memantau aktivitas mitranya.

Selain menyediakan jasa pengantaran, pihak penyedia jasa ojek online juga mengekspansi kegiatan bisnisnya dalam beberapa layanan lain diantaranya, jasa pembelian makanan dan minuman, jasa pembelian tiket bioskop, penjualan pulsa, voucher game, jasa pembersihan tempat tinggal, bahkan sampai pada jasa pijat memijat.

Perkembangan yang pesat dari penyedia jasa ojek online tentu saja tidak lepas dari partisipasi pengguna dan mitra pengemudinya. Berdasarkan fajta yang ada, peningkatan jumlah pengguna dikarenakan banyaknya pengguna yang mempercayakan jasa ojek online untuk memenuhi kebutuhannya ${ }^{10}$. Hal ini tentu saja berdampak pada semakin banyaknya kebutuhan pihak penyedia jasa ojek online dalam memiliki mitra pengemudi ojek online. Sehingga membuka kesempatan yang luas kepada masyarakat untuk bergabung menjadi mitra pengemudi ojek online.

Adapun prosedur kemitraan yang ditawarkan oleh penyedia jasa ojek online kepada mitra pengemudi ojek online yaitu dengan suatu perjanjian kemitraan, dengan beberapa persyaratan sesuai dengan kebutuhan perusahaan penyedia jasa ojek online. Adapun beberapa persyaratan umum tersebut diantaranya ialah:

1. Usia minimum 21 tahun

2. Memiliki kendaraan yang layak

3. Memiliki STNK

4. Memiliki SIM C

5. Memiliki Surat Keterangan Catatan Kepolisian (SKCK) atau KTA bagi anggota Polri

6. Lulus tes kelayakan dari staf Uber (Training)

7. Memiliki smartphone Android 4.0 atau iPhone $4 S$

Ketentuan terkait perjanjian kemitraan sejatinya telah diatur secara umum dalam pasal 1338 jo pasal 1320 KUH Perdata, dan secara

10 Ayu Aziza dan Popon Rabi Adawia, "Analisis Perkembangan Industri Transportasi Online di Era Inovasi Disruptif (Studi Kasus PT.Gojek Indonesia)," Jurnal Cakrawala 18 (2 September 2018). 
khusus dalam PP No 44 Thn 1997 tentang kemitraan 11. Dengan dalih demi tercapainya efektivitas dan efisiensi waktu, perjanjian kemitraan pengemudi ojek online diwujudkan dalam perjanjian baku. Pihak pertama telah lebih dulu merumuskan terkait perjanjian yang akan dilaksanakan antara kedua belah pihak. Lalu pihak kedua meninjau perjanjian yang telah dibuat untuk diputuskan langkah selanjutnya apakah akan dilanjutkan dengan kesepakatan atau tidak diadakannya perjanjian.

Hal tersebut tidaklah terlarang, meskipun bergaining position nampak belum terpenuhi, mitra hanya memiliki dua pilihan take it or leave it. Akan tetapi apabila para pihak mengedapankan asas amanah, keadilan dan keseimbangan dalam perumusan perjanjian kemitraan, maka kandungan dan manfaat akan sejalan dengan tujuan para pihak 12. Karena asas kebebasan dalam berkontrak tetap terbatasi dengan asas kemaslahatan dan causa yang halal. Sehingga tidak menyebabkan perubahan status kebolehan dalam kegiatan bermuamalah menjadi terlarang. Maka nampak terlihat i'tikad baik harus menjadi modal yang paling utama bagi para pihak ${ }^{13}$.

Dalam pengaplikasian konsensus dalam perjanjian tidak selalu ditandai dengan tanda tangan yang dibubuhi dengan materai 6000 . Apalagi di era digital saat ini, perkembangan teknologi yang semakin pesat membuat perjanjian sudah berbentuk elektronik atau biasa kita kenal dengan E-Contract, sesuai dengan kebutuhan kelompok/masyarakat pada masa itu ${ }^{14}$. Konsensual dapat terjalin hanya dengan dengan mengklik setuju dari perjanjian yang disuguhkan oleh pihak penyedia jasa ojek online. Pencapaian konsensual memang terkesan begitu mudah. Sehingga dapat diasumsikan tidak semua mitra pengemudi ojek online memahami

${ }^{11}$ Sonhaji, "Aspek Hukum Layanan Ojek Online Perspektif UndangUndang Nomor 13 Tahun 2003 Tentang Ketenagakerjaan."

12 Muftadin, "Dasar-Dasar Hukum Perjanjian Syariah Dan Penerapannya Dalam Transaksi Syariah," Al-Adl, 2018, 100.

13 Nurhidayatulloh, Febrian, dkk, "Forsaking Equality: Examine Indonesia State Responbility on Polygamy to The Marriage Rights in CEDAW," 2, 18 (2018): 182-93.

14 Muhammad Muhtarom, "Pengaruh Budaya Hukum Dalam Kepatuhan Hukum Dalam Masyarakat," SUHUF 27 (November 2015): 12146. 
implikasi konsensus bagi mereka. Padahal implikasi konsensual tersebut tentu saja mengarah pada Pasal 1338 KUH Perdata yang berbunyi :

Semua perjanjian yang dibuat secara sah berlaku menjadi undangundang bagi mereka yang membuatnya (pacta sunt servanda). Suatu perjanjian tidak dapat ditarik kembali selain dengan kesepakatan kedua belah pihak, atau karena alasan-alasan yang oleh undang-undang dinyatakan cukup untuk itu. Semua perjanjian harus dilaksanakan dengan i'tikad baik.

Selanjutnya Undang-Undang Nomor 11 Tahun 2008 tentang Informasi Transaksi Elektronik pada pasal 18 ayat 1 telah menambahkan "Transaksi yang dituangkan dalam kontrak elektronik mengikat para pihak". Sehingga terbentuklah sebuah hubungan kontraktual antara mitra pengemudi ojek online dengan pihak penyedia jasa ojek online dalam ikatan perjanjian kemitraan.

Kamus Besar Bahasa Indonesia mendefinisikan kata mitra sebagai teman, rekan, pasangan kerja. Menurut Hafsah, kemitraan adalah suatu strategi bisnis yang dilakukan oleh dua pihak atau lebih dalam jangka waktu tertentu untuk meraih keuntungan bersama dengan prinsip saling membutuhkan dan saling membesarkan. Karena merupakan stratergi bisnis, maka keberhasilan kemitraan sangat ditentukan oleh adanya kepatuhan diantara yang bermitra dalam menjalankan etika bisnis ${ }^{15}$. Adapun beberapa asas - asas yang terkandung dalam kemitraan, yaitu :

1. Asas kesejajaran kedudukan mitra

2. Asas saling membutuhkan

3. Asas saling mematuhi etika bisnis

4. Asas saling menguntungkan.

Perjanjian kemitraan yang diatur dalam PP No. 44 Thn 1997 tentang Kemitraan memuat empat syarat kemitraan, yaitu: adanya hubungan kerjasama antara dua pihak atau lebih, adanya relasi hubungan yang setara antara kedua belah pihak, adanya keterbukaan atau transparansi, adanya hubungan yang saling

15 Muhammad Jafar Hafsah, Kemitraan Usaha Konsepsi dan Strategi (Jakarta: PT. Pustaka Sinar Harapan, 2000). 
menguntungkan terhadap kedua belah pihak yang mengikatkan diri ke dalam perjanjian kemitraan.

Akan tetapi, perjanjian kemitraan yang diterapkan, terkesan sebagai pengelakan terhadap Undang-Undang Nomor 13 Tahun 2003 tentang Ketenagakerjaan. Tidak adanya unsur perintah, pekerjaan dan upah didalam perjanjian kemitraan membuat hukum ketenagakerjaan tidak dapat menjangkaunya. Sehingga perjanjian kemitraan akan patuh dan tunduk pada aturan KUH Perdata, Undang-Undang Kemitraan, serta Peraturan Pemerintah.

Sehingga kedudukan para mitra dalam perjanjian kemitraan memiliki keterkaitan yang erat. Karena adanya upaya saling menguntungkan para pihak. Pihak penyedia jasa ojek online tidak memiliki tuntutan dalam memastikan jumlah pekerjaan maupun upah terhadap mitranya. Akan tetapi adanya kewajiban untuk memberikan pilihan pekerjaan dan upah yang sesuai dengan kebermanfaatan yang telah diberikan mitranya. Begitu pula dengan mitra pengemudi ojek online, mereka tidak memiliki kewajiban terkait waktu kerja serta jobdesk kerja yang pasti. Sehingga adanya kesempatan dalam menentukan waktu dan jenis pekerjaan yang dikehendaki menggambarkan perjanjian kemitraan yang mengedepankan mutualisme diantara para pihak.

\section{Perlindungan Hukum Mitra Pengemudi Pasca Akuisisi Uber Oleh Grab}

Pada hari senin 26 Maret 2018 Grab resmi mengakuisisi Uber. Sehingga secara otomatis Uber selaku penyedia jasa ojek online tidak lagi dapat memberikan kebermanfaatan kepada mitra pengemudinya. Adapun alasan Grab melakukan pengakuisisian di Indonesia didasarkan pada beberapa alasan, diantaranya alasan keuntungan operasional, keuntungan finansial, pertumbuhan perusahaan, dan potensi diversifikasi ${ }^{16}$.

Uber merupakan perusahaan teknologi penyedia jasa layanan transportasi berbasis online pertama di dunia. Munculnya inovasi teknologi dan transportasi yang berbuah aplikasi, merupakan hal yang sangat baru kala itu. Dimana metode bertransportasi dilakukan dengan cara manual yang mana sebagai penumpang harus mencari

${ }^{16}$ Inka Sumarlislamsiar Samsiari Gijipang, “Akuisisi Perusahaan Uber Oleh Grab Di Indonesia” (Skripsi, Jember, Universitas Jember, 2019). 
atau mendatangi lokasi tertentu seperti menghampiri pangkalan ojek, menunggu angkutan kota di pinggir jalan, ataupun menunggu bus di halte. Uber menjadi salah satu pencetus ide pertama pemanfaatan teknologi informasi pada pola bertranportasi.

Uber merupakan salah satu perusahaan penyedia jasa ojek online yang berasal dari Amerika Serikat, dan cakupan pangsa pasarnya sudah merambat sampai dunia Internasional ${ }^{17}$. Indonesia merupakan salah satu negara yang tidak luput dari sasaran pasar Uber. Tepatnya tahun 2014 perusahaan penyedia jasa ojek online Uber telah masuk di Indonesia. Akan tetapi perkembangannya tidak begitu signifikan, karena adanya pesain dari Gojek dan Grab.

Kehadiran penyedia jasa ojek online lokal Indonesia merupakan salah satu penyebab perkembangan Uber di Indonesia tertatih-tatih. Ditambah lagi dengan adanya penyedia jasa ojek online Grab yang berasal dari Asia Tenggara. Gojek dan Grab mampu mewujudkan persaingan yang kompetitif dalam ranah penyedia jasa ojek online. Konsep yang diusungnya pun hampir sama diantara semuanya. Mulai dari jasa yang disediakan sampai pada sistem kemitraan yang diterapkan pada mitra pengemudinya.

Terkait pengakuisisian terhadap Uber, ialah merupakan suatu poin isi perjanjian yang telah dinyatakan dalam suatu ketentuan oleh pihak Uber kepada Mitranya. Bahwasanya Uber dapat melakukan perubahan terkait layanannya dari waktu ke waktu dengan cara sepihak, dan pengguna maupun mitra pengemudi ojek online dianggap setuju apabila tetap menggunakan layanan dan bermitra dengan Uber ${ }^{18}$. Persyaratan dan ketentuan ini memang tidak begitu terekspose kepada para pengguna maupun mitra pengemudi Uber.

Sehingga nampak terlihat Perjanjian kemitraan memiliki kelemahan jika dibandingkan dengan perjanjian kerja pada umumnya. Pasalnya apabila adanya pemberhentian secara sepihak, maka tidak perlu adanya ganti rugi akan hal itu. Hilangnya mutualisme dari salah satu pihak merupakan suatu hal pertanda

\footnotetext{
17 Anthony Kevin, "Mengenal Penguasa Transportasi Online di Berbagai Negara," CNBC Indonesia (blog), 2018, https://www.cnbcindonesia.com/news/2018021714483-44692,.

18 Uber B.V, "Persyaratan dan Ketentuan," Uber (blog), 2019, https://www.uber.com/id/legal/terms/id.
} 
perjanjian kemitraan akan berakhir. Karena terkait perubahan atau pengakhiran kemitraan, masing-masing tidak perlu menyepakatinya. Terlihat keotentikan perjanjian kemitraan bukan pada batas waktu, akan tetapi lebih kepada batas kebermanfaatan yang dapat diberikan masing-masing pihak.

Sama halnya dengan pengakuisisian Uber oleh Grab, secara otomatis mitra pengemudi ojek online Uber berakhir dengan sendirinya. Hanya saja perlu adanya kedewasaan dari Grab sebagai perusahaan yang mengakuisisi Uber untuk menaungi mitra pengemudi Uber terdahulu. Karena pihak Uber sudah tidak bisa lagi memberikan mutualisme kepada mitra pengemudinya ${ }^{19}$.

Dalam hal ini, Grab selaku perusahaan yang mengakuisisi Uber telah bersedia mengalihkan mitra pengemudi Uber untuk bertransformasi menjadi mitra pengemudi Grab, dengan melakukan daftar ulang yang akan diberi bimbingan oleh Grab, dengan batas waktu tertentu. Namun bagi mitra pengemudi Uber yang tidak melakukan daftar ulang kepada Grab, dianggap sudah tidak berkenan menjadi mitra pengemudi Uber yang bertransformasi menjadi Grab. Lebih tegas Managing Director Grab Indonesia Ridzki Kramadibrata menjelaskan mitra pengemudi Grab yang lama tidak akan terganggu dengan bertambahnya mitra pengemudi dari Uber karena pangsa pasar Uber juga ikut beralih kepada Grab 20.

Sehingga nampak terlihat mitra pengemudi ojek online tetap berada dalam posisi yang lemah dalam perjanjian kemitraan ini. Karena tidak adanya perundingan terkait keputusan Uber, untuk menjual saham kepemilikan kepada pihak Grab. Hanya ada pemberitahuan dan himbauan untuk mitra pengemudinya agar mengurus kepindahannya pada Grab. Harapan mendapatkan uang pesangon ataupun kompensasi layaknya pemutusan hubungan kerja hanyalah angan bagi mitra pengemudinya. Sehingga kasus ini menjadi penjelas akan kedudukan para pihak dalam perjanjian

19 Nurhidayatulloh, Febrian, dkk, “Forsaking Equality: Examine Indonesia State Responbility on Polygamy to The Marriage Rights in CEDAW."

20 Andri Donnal Putra, "Grab akuisisi Uber, Ini dampak bagi penumpang dan mitra pengemudi," Kompas (blog), 2018, https://ekonomi.kompas.com,. 
kemitraan dan akan menjadi percontohan dalam kasus berakhirnya perjanjian kemitraan, terkhusus dalam ranah perjanjian kemitraan ojek online.

Revitalisasi pemahaman para mitra ojek online harus dilakukan, agar rasa aman dalam keberlangsungannya perjanjian kemitraan tidak lagi mendarah daging. Perjanjian kemitraan ojek online hanyalah penunjang jalinan kerjasama. Ketika mutualisme tidak lagi dapat diaktualisasikan, seketika perjanjian terhapuskan, tanpa adanya tuntunan atas kerugian.

\section{Penutup}

Berdasarkan pemaparan-pemaparan di atas, Perjanjian kemitraan yang diterapkan oleh penyedia jasa ojek online dengan mitra drivernya hanyalah sebatas mutualisme. Ketika kebermanfaatan tidak dapat diberikan oleh salah satu pihak maka pihak lain tidak dapat menuntut. Dengan sendirinya perjanjian kemitraan akan berakhir ketika salah satu pihak tidak dapat memberikan kemanfaatan pada pihak lainnya. Akuisisi yang dilakukan Grab terhadap Uber menjadikan pembelajaran bagi mitra pengemudi ojek online. Sehingga perlu kita sadari bersama bahwa perjanjian kemitraan sangat jauh berbeda dengan perjanjian kerja yang dinaungi oleh Undang-Undang Nomor 13 Tahun 2003 Tentang Ketenagakerjaan.

\section{Daftar Pustaka}

Adawia, Ayu Aziza dan Popon Rabi. "Analisis Perkembangan Industri Transportasi Online di Era Inovasi Disruptif (Studi Kasus PT.Gojek Indonesia)." Jurnal Cakrawala 18 (2 September 2018).

Amin, Muhammad. "Implementasi Undang-Undang Nomor 1 Tahun 2013 Terhadap Lembaga Keuangan Mikro Syariah yang Berbadan Hukum Koperasi." Jurisdictie: Jurnal Hukum dan Syariah 10, 2019

Gijipang, Inka Sumarlislamsiar Samsiari. "Akuisisi Perusahaan Uber Oleh Grab Di Indonesia.” Skripsi, Universitas Jember, 2019.

Hafsah, Muhammad Jafar. Kemitraan Usaha Konsepsi dan Strategi. Jakarta: PT. Pustaka Sinar Harapan, 2000.

Imron Mustofa. "Jendela Logika dalam Berfikir: Deduksi dan Induksi sebagai Dasar Penalaran Ilmiah." EL-BANAT: Jurnal Pemikiran dan Pendidikan Islam Volume 6, Nomor 2 Desember 2016

Iriani, Tita Yulia. "Analisis Dampak Layanan Go-Food Terhadap Omzet Penjualan Rumah Makan Di Kota Bandung.” Skripsi, Pasundan, 2018. 
Kevin, Anthony. "Mengenal Penguasa Transportasi Online di Berbagai Negara." CNBC Indonesia (blog), 2018. https://www.cnbcindonesia.com/news/2018021714483-44692,.

Lora, Vivian. "Tinjauan Hukum Terhadap Perjanjian Kemitraan Antara PT.Gojek Indonesia Cabang Medan Dengan Driver Gojek." Skripsi, Universitas Sumatera Utara, 2018.

Marzuki, Peter Mahmud. Penelitian Hukum. Jakarta: Prenada Media Group, 2010.

Muftadin. "Dasar-Dasar Hukum Perjanjian Syariah Dan Penerapannya Dalam Transaksi Syariah." Al-Adl, 2018, 100.

Muhammad Muhtarom. "Pengaruh Budaya Hukum Dalam Kepatuhan Hukum Dalam Masyarakat." SUHUF 27 (November 2015)

Nirmala, Ronna. "Grab Ambil Alih Bisnis dan Aset Uber di Asia tenggara." Beritagar.id (blog), 2018. https://beritagar.id/artikelamp/berita,.

Nurhidayatulloh, Febrian, dkk. "Forsaking Equality: Examine Indonesia State Responbility on Polygamy to The Marriage Rights in CEDAW," 2, 18 (2018)

Pratama, Geistiar Yoga. "Perlindungan Hukum Terhadap Data Pribadi Pengguna Jasa Transportasi Online dari Tindakan Penyalahgunaan Pihak Penyedia Jasa Berdasarkan UU No 8 Tahun 1999 tentang Perlindungan Konsumen.” Jurnal Masalah Hukum 5 (2016)

Putra, Andri Donnal. "Grab akuisisi Uber, Ini dampak bagi penumpang dan mitra pengemudi." Kompas (blog), 2018. https://ekonomi.kompas.com,.

Sonhaji. "Aspek Hukum Layanan Ojek Online Perspektif Undang-Undang Nomor 13 Tahun 2003 Tentang Ketenagakerjaan." Adminitrative law \& Governance Journal 1 (4 November 2018)

Uber B.V. "Persyaratan dan Ketentuan." Uber (blog), 2019. https://www.uber.com/id/legal/terms/id.

Yochi Ayunita. Annalisa Yahanan dan Muhammad Syaifuddin. "Perlindungan Hukum Terhadap Pengemudi Taksi (mitra) Berbasis Online pada PT.Grab Indonesia." Fakultas Hukum Unsri Palembang, 2019 